\title{
Youth in a Climate Crisis: Improving how the Victorian Government Engages with Young People on Climate Change
}

\author{
Emma Keech
}

(Received 26 October 2021; accepted 30 October 2021; first published online 19 November 2021)

This research was conducted between March and October 2019 and was inspired by the young activists participating in the School Strike movement. This research assessed whether the Victorian government adequately engaged with young people on climate change decision-making, identified barriers to engagement and developed practical recommendations.

An initial review of the two most relevant policy documents, Victoria's Youth Policy Building Stronger Youth Engagement in Victoria and Victoria's Climate Change Framework, identified a disconnect between the rhetoric around youth engagement from the Victorian state government, and the reality of youth engagement on climate change decision-making. Interviews conducted with six participants from youth advocacy organisations, academia and state government, confirmed the findings of the initial document review, revealing dissatisfaction with the Victorian government's current approach to youth engagement in the environment sector. None of the participants considered the current engagement to be 'adequate', and only one participant was able to identify an example of the Victorian government consulting with young people on climate policy.

Participants were asked about the perceived barriers to improved engagement, and what could be done to overcome them. Extending the franchise to 16-year olds and setting quotas for young people on boards were among the more radical suggestions that emerged. Some smaller, more politically palatable steps were also suggested, including establishing a formal mechanism for young people to submit ideas, concerns and comments (such as a 'Youth Climate Expert Reference Group'), more professional development programmes promoting youth engagement for staff across government (not just for those whose work already brings them in contact with young people), and increased support for holistic civics education in schools.

The Victorian government has strong youth and climate policies, but these do not speak to each other. The sentiment of inclusivity, respect and partnership espoused in the Youth Policy is not reflected in climate change decision-making. This is problematic, given the unique ways that climate change will impact young people's future health and wellbeing. While the exclusion of young people from decision-making processes is an entrenched problem that defies quick fixes, this research identified the current state of engagement and offered practical steps to improve, namely education (civics education and professional development), empowerment (ensuring young

\footnotetext{
A thesis submitted as partial fulfilment of the requirements for the degree of Bachelor of Arts International Studies (Hons) in the School of Global Studies, Social Science and Planning at RMIT University.
}

This manuscript is an original work that has not been submitted to nor published anywhere else.

Supervisor: Dr Blanche Verlie 
people have a seat at the table) and reflection and restructure (reviewing current consultation practices, and making structural change).

Citation and digital source for thesis. Keech, E. (2019). Youth in a Climate Crisis: Improving how the Victorian Government Engages with Young People on Climate Change. [Unpublished honours thesis]. RMIT University.

Emma Keech completed her Bachelor of Arts (International Studies) (Honours) in 2019 and was inspired by the School Strikers to investigate how the Victorian Government could better include young people in their decision-making on climate change. She now works in the Australian Public Service. Email: eskeech@gmail.com

Cite this article: Keech, E. (2022). Youth in a Climate Crisis: Improving how the Victorian Government Engages with Young People on Climate Change. Australian Journal of Environmental Education 38, 119-120. https://doi.org/10.1017/aee.2021.25 